\title{
CARTAS Y DIBUJOS ACERCA DE UNA INSCRIPCIÓN ROMANA DESAPARECIDA: EL ARA DE TRABANCA (VILAGARCÍA DE AROUSA) $^{1}$
}

\author{
Carlos Santos Fernández \\ IES Antón Losada Diéguez
}

1 Sirva esta primera nota para agradecer a las direcciones y personal del Arquivo do Museo do Pobo Galego (en adelante MPoboG), del Arquivo da Real Academia Galega (RAG), del Arquivo do Museo de Pontevedra (MdP) y de la Biblioteca Xeral da Universidade de Santiago (BUS) las facilidades proporcionadas para la realización de este trabajo y los permisos de reproducción de las imágenes que lo ilustran, agradecimiento que quiero personalizar en Rosa Méndez, bibliotecaria del Museo do Pobo Galego quien, al proporcionarme la carta de Fernández Gil a López Ferreiro, estimuló mi interés por este monumento epigráfico.

Copyright: (C) 2016 CSIC. Este es un artículo de acceso abierto distribuido bajo los términos de una licencia de uso y distribución Creative Commons Attribution (CC-by) España 3.0.

Cómo citar/Citation: Carlos Santos Fernández, "Cartas y dibujos acerca de una inscripción romana desaparecida: el ara de Trabanca (Vilagarcía de Arousa)", Cuadernos de Estudios Gallegos, 63, núm. 129 (2016), págs. 91-123, DOI: http://dx.doi.org/10.3989/ceg.2016.129.03 


\section{CARTAS Y DIBUJOS ACERCA DE UNA INSCRIPCIÓN ROMANA DESAPARECIDA: EL ARA DE TRABANCA (VILAGARCÍA DE AROUSA)}

RESUMEN

Edición y estudio de cinco documentos (tres cartas y dos dibujos) firmados por Juan Fernández Gil y Casal entre 1909 y 1917 que proporcionan el texto íntegro, las características del soporte y las circunstancias del hallazgo del ara de Trabanca da Torre (Vilagarcía de Arousa, Pontevedra), encontrada hacia 1890 y que en 1909 ya se consideraba perdida. La temprana desaparición del ara -que indujo a algunos investigadores a poner en duda su existencia-, explica que lo publicado a lo largo del siglo XX acerca de esta pieza se limite a referencias tangenciales (la de García de la Riega, en 1904, para apuntalar su tesis helenística en la polémica entre celtófobos y celtómanos), o a lecturas parciales y sin atención a las características del soporte. La única finalidad de esta colaboración, al margen de relecturas epigráficas o interpretaciones del texto, es dar a conocer los cinco documentos (cuatro inéditos y uno publicado en 2012) conservados en el Museo do Pobo Galego, en la Real Academia Galega y en el Museo de Pontevedra, que pueden servir como fuente para el estudio indirecto del ara de Trabanca hasta que se consiga-como esperamos-su recuperación.

Palabras Clave: Epigrafía. Ara romana. Trabanca da Torre (Vilagarcía de Arousa, Pontevedra). Fuentes. Epistolario. Dibujos. 1909-1917.

\section{CARTAS E DEBUXOS SOBRE UNHA INSCRICIÓN ROMANA DESAPARECIDA: A ARA DE TRABANCA (VILAGARCÍA DE AROUSA)}

RESUMO

Edición e estudo de cinco documentos (tres cartas e dous debuxos) asinados por Juan Fernández Gil y Casal entre 1909 e 1917 que proporcionan o texto íntegro, as características do soporte e as circunstancias do achado da ara de Trabanca da Torre (Vilagarcía de Arousa, Pontevedra), atopada arredor de 1890 e que en 1909 considerábase xa perdida. A temperá desaparición da ara -que levou a algúns investigadores a dubidar da súa existencia-, explica que o publicado ó longo do século XX acerca desta peza sexan referencias tanxenciais (a de García de la Riega, no 1904, para reforzar a súa tese helenística na polémica entre celtófobos e celtómanos), ou lecturas parciais que non prestan atención ás características materiais da peza. A finalidade desta colaboración, allea a relecturas epigráficas ou a interpretacións do texto, é dar a coñecer os cinco documentos (catro inéditos e un publicado no ano 2012) conservados no Museo do Pobo Galego, na Real Academia Galega y no Museo de Pontevedra), que poden servir como fonte para o estudo indirecto da ara de Trabanca, namentres non sexa, como agardamos, recuperada.

Palabras clave: Epigrafía. Ara romana. Trabanca da Torre (Vilagarcía de Arousa, Pontevedra). Fontes. Epistolario. Debuxos. 1909-1917.

\footnotetext{
LETTERS AND DRAWINGS REGARDING A LOST ROMAN INSCRIPTION: THE ALTAR STONE IN TRABANCA (VILAGARCÍA DE AROUSA, PONTEVEDRA, SPAIN) ABSTRACT

Edition and study of five documents (three letters and two drawings) signed by Juan Fernández Gil y Casal, 1909 - 1917, reveal the complete text, the physical characteristics as well as the circumstances of the discovery of a Roman altar that was found in 1890 in Trabanca da Torre (Vilagarcía de Arousa, Pontevedra), that disappeared before 1909. This early disappearance leads some researchers to question their existence, and it also explains the news that were published in the twentieth century about the altar which have been limited to tangential references or incomplete transcriptions, without any attention to the physical characteristics of the piece. The only aim of this collaboration, which excludes reviews or textual interpretations, is to present the five documents (four that are not still published and another one that has been recently published in 2012) which are preserved in Museo do Pobo Galego, Real Academia Galega and Museo de Pontevedra, documents that can serve as an indirect source for the study of Trabanca's altar stone until its recovery as we hope.

KeY wORDS: Epigraphy. Roman altar stone. Trabanca da Torre (Vilagarcía de Arousa, Pontevedra, Spain). Sources. Letters. Drawings. 1909-1917.
} 
Recibido/Received: 20/01/2016

Aceptado/Accepted: 22/06/2016

$\mathrm{L}$

a redacción de una biografía de Antonio López Ferreiro entre los años 2008 y $2011^{2}$ nos obligó a manejar un copioso fondo archivístico, propiciando el hallazgo de algunos documentos que, intuimos, trascienden la función de mera fuente del decurso vital del canónigo, historiador y novelista compostelano. Es el caso de una carta que se conserva en el Museo do Pobo Galego, dirigida por Juan Fernández Gil a López Ferreiro el 8 de mayo de 1909 para consultar al anciano historiador la interpretación de una inscripción romana hallada en Trabanca da Torre, misiva que proporciona - a tenor de lo que hemos podido averiguar- la más temprana y completa descripción de un ara perdida desde la primera década del siglo XX.

Al cotejar la información que proporciona la carta con los repertorios de epigrafía romana de Galicia entendimos que el interés de la epístola superaba la de simple fuente de la biografía ferreriana, pues aportaba una lectura completa del desaparecido epígrafe de Trabanca da Torre. Pero Fortuna fue, en esta ocasión, dadivosa: un año después, con la biografía de López Ferreiro entregada a los editores y mientras revisábamos los papeles de Eladio Oviedo Arce depositados en el archivo de la Real Academia Galega, encontramos una cuartilla firmada por Fernández Gil con dos dibujos -vista anterior y posterior- del monumento de Trabanca da Torre.

Posteriormente, ya incursos en la preparación de este trabajo, localizamos en el Museo de Pontevedra otros documentos relativos al ara de Trabanca: una aguada de Fernández Gil destinada a la Exposición Regional de Galicia de 1909 y dos cartas del mismo remitente, fechadas en mayo de 1909 y marzo de 1917, dirigidas a Casto Sampedro.

Gracias a la amabilidad de las citadas instituciones (Museo do Pobo Galego, Real Academia Galega y Museo de Pontevedra) reproducimos los cinco documentos para dejar constancia de las características físicas de la pieza y del texto completo de una inscripción (desgraciadamente) desaparecida.

2 Carlos Santos Fernández, Antonio López Ferreiro (1837-1910). Canónigo compostelano, historiador y novelista, Santiago, Cabildo de la Catedral de Santiago - Consorcio de Santiago Alvarellos Editora, 2012. 
No es nuestra intención hacer nuevas lecturas o interpretaciones de la lápida de Trabanca: versados doctores tiene la capilla de la epigrafía latina... Solo pretendemos presentar un panorama de lo que se ha publicado acerca de esta pieza $\mathrm{y}$, fundamentalmente, ofertar a los epigrafistas una serie de documentos inéditos que puedan aportar un rayo de luz al conocimiento del ara de Trabanca.

\title{
BIBLIOGRAFÍA SOBRE EL ARA DE TABANCA
}

En diciembre del año 1904 salieron de la imprenta pontevedresa de A. del Río y Miró los primeros ejemplares de Galicia antigua. Discusiones acerca de su geografia y de su historia, el enjundioso y beligerante libro escrito por Celso García de la Riega para rebatir las tesis celtistas de la historia de Galicia, fundamentalmente las sostenidas por Murguía, al que en Galicia antigua se fustiga con fruición ${ }^{3}$. García de la Riega sustituye la arraigada celtofilia de la historiografía galaica coetánea por una celtofobia ${ }^{4}$ que lo mueve a buscar los orígenes históricos de Galicia en un quimérico conglomerado griego, púnico, vasco e ibérico, de tal modo que, en palabras de María del Mar Zarzalejos sustituye una teoría plagada de defectos por otra no más verosímil ${ }^{5}$.

Desde su posicionamiento celtófobo, García de la Riega tenía que aferrarse a los testimonios arqueológicos que pudieran apuntalar sus tesis acerca de la relevante huella helénica en Galicia. ¿Cómo obviar la aparición, en las proximidades de Vilagarcía de Arousa, de una inscripción votiva aparentemente (la interpretación es discorde) dedicada a Ares, el dios griego? Así lo explicaba García de la Riega:

\begin{abstract}
En diversas comarcas de Galicia tuvo también culto importante el dios Marte, bajo el nombre griego de Ares, del cual quedaron elocuentes supervivencias. En toda la Edad Media y aun a principios del siglo XV era frecuentísimo no solo el apellido, sino también el nombre propio de Ares: Ares Pérez, Ares Saavedra [...] Ares se
\end{abstract}

\footnotetext{
3 Como ejemplo del aprecio que merecían a García de la Riega tanto las tesis celtistas como los motivos que, a su entender, inspiraban a Murguía sirvan, extraídas aleatoriamente, las siguientes líneas: La teoría celto-galaica carece en absoluto de los apoyos indispensables, no ya para que prevalezca, ni siquiera para ser tomada en consideración [...] El propósito de dar bases étnicas al sistema de la autonomía gallega ha sido causa, sin duda, de que el Sr. Murguía haya extremado su criterio celtista. (Celso GARcía DE LA RIEGA, Galicia antigua. Discusiones acerca de su geografía y de su historia, Pontevedra, Diputación Provincial de Pontevedra, 1904, págs. 422-424).

4 El profesor Barreiro Fernández califica a Murguía y a García de la Riega, respectivamente, de celtómano y celtófobo (Xosé Ramón Barreiro Fernández, Murguía, Vigo, Galaxia, 2012, pág. 811). 5 María del Mar Zarzalejos Prieto, "Aproximación al panorama historiográfico de la cultura castreña en la provincia de Orense (I)", Cuadernos de Prehistoria y Arqueología de la Universidad Autónoma de Madrid, 16 (1991), pág. 311.
} 
llaman un pueblo y una ría en el seno brigantino, varios castros y otras localidades [...] Cerca de la villa de Carril se encontró una inscripción de un voto dedicado a Ares. Este nombre de divinidad solo pudo ser introducido en Galicia por los griegos: los romanos usaban en nuestro país, lo mismo que en los demás, el de Marte, pues así lo demuestran varias inscripciones de Coruña, Tuy y otros puntos ${ }^{6}$.

Por lo que hemos podido averiguar, en este párrafo se halla la primera mención impresa al ara de Trabanca: Cerca de la villa de Carril se encontró una inscripción de un voto dedicado a Ares. Una referencia tangencial, que no describe el soporte de la inscripción, ni transcribe el texto; que no concreta el lugar del hallazgo, ni el factor, ni las circunstancias en que se produjo, ni dónde se conserva. Nada de esto respondía a las necesidades de García de la Riega, al que bastaba con mencionar aquel documento epigráfico que servía como un grano más de arena para la construcción de su edificio sobre las raíces helénicas de Galicia. En cualquier caso, se trata de la primera referencia impresa al ara de Trabanca que hemos localizado, que permite situar en 1904 la fecha ante quam se produjo su hallazgo aunque, como veremos, cabe retrotraer el descubrimiento a la penúltima década del siglo XIX.

Ocho años después, en 1912, se publicó Mondariz, Vigo, Santiago, una guía de viajes por Galicia en la que colaboraron Emilia Pardo Bazán, Alfredo Vicenti o el propio Celso García de la Riega. En un capítulo de este libro, firmado con el criptónimo X, se propone un itinerario epigráfico por la Galicia atlántica en el que puede leer: En el lugar de Trabanca, un kilómetro al oriente de la estación, se descubrió no hace muchos años por los señores Fernández Gil y Casal, la interesante ara consagrada al Marte de los griegos, con una como caja de sepultura al pie. Es evidente que el anónimo redactor de estas líneas comulgaba con la tesis helenista propuesta por García de la Riega ocho años antes, que vinculaba el ara con el griego Ares.

Una de las referencias más conocidas al ara de Trabanca-citada generalmente como primera noticia- vio la luz en 1916, en un artículo titulado "Apuntes arqueológicos" "que Juan Fernández Gil y Casal firmó en el Boletín de la Real Academia de la Historia a instancias del académico Francisco Fernández de Bethencourt.

6 C. García de la Riega, Galicia antigua..., págs. 535-536.

7 X, "Indicaciones epigráficas desde la Guardia a Santiago" en Mondariz, Vigo, Santiago. Guía del turista, Madrid, Sucesores de Rivadeneyra, 1912, pág. 68.

8 F. [i. e: J.] Fernández Gil y Casal, "Apuntes arqueológicos", Boletín de la Real Academia de la Historia, 68 (enero-junio de 1916), págs. 29-46. 
El trabajo de Fernández Gil (cuyo manuscrito original, autógrafo y firmado por el autor en Vilagarcía el 13 de enero de 1915 se conserva en el archivo de la Academia de la Historia $)^{9}$ conjuga la descripción arqueológica de algunos asentamientos del entorno de Vilagarcía y de los materiales exhumados con hipótesis etimológicas acerca de la toponimia comarcal, algunas tan arriesgadas como:

Palmeira pudiera derivarse de $\pi \dot{\alpha} \lambda \mu \eta$, refiriéndose a los que usan el escudo llamado en latín parma. Caramiñal, de $\kappa \alpha ́ \rho \alpha$ y $\mu$ ívuv $\theta \alpha$, por los que tienen la cabeza, el casco pequeño, propio de la raza ibérica [...] Goyanes, sitio alto, así como Guillán en la falda del monte Jiabre, cerca de Villagarcía, por illa, muerte, an, allí, igual a lugar de muerte o de sacrificio, lo que vendría a corroborar la aserción planteada por algunos escritores gallegos sobre sacrificios del rito celta, mejor ibérico, sobre este monte $e^{10}$.

A tan aventuradas hipótesis etimológicas se refería el marqués de Cerralbo en su informe sobre los "Apuntes arqueológicos" al escribir que el doctísimo Director [de la Academia, el P. Fidel Fita] ha mirado con indulgencia la parte filológica ${ }^{11}$ del trabajo de Fernández Gil.

Al margen de los manifiestos dislates etimológicos, la segunda parte de la colaboración firmada por Fernández Gil se centra en la descripción de una serie de yacimientos arqueológicos del entorno de Vilagarcía: los petroglifos de Os Ballotes y Meadelo y los castros de Alobre, Lobeira, Bouza y Gudín. Precisamente al referirse al Castro Gudín, escribe Fernández Gil:

Este castro es el más importante de todos por su nombre, por su altitud, que domina todos los otros, y es el que establece el lazo de unión con los demás del interior del país. Entre el nombre de este

\footnotetext{
9 Juan Fernández Gil y CASAl, Apuntes arqueológicos, manuscrito autógrafo, 16 hs., $4^{\circ}$, firmado “J. Fernández Gil y Casal, C. de la R. Academia Gallega, Vilaga de Arosa, 13 ene 1915" (Real Academia de la Historia, CAPO/9/7967/07(2)).

${ }^{10}$ F. Fernández Gil y CASAL, “Apuntes ...”, pág. 32.

${ }^{11}$ Enrique de Aguilera y Gamboa, marqués de Cerralbo, "Apuntes arqueológicos por el Sr. D. Juan Fernández Gil y Casal, en comunicación manuscrita que ha dirigido a la Real Academia de la Historia", Boletín de la Real Academia de la Historia, 68 (enero-junio de 1916), pág. 46. La lectura de este informe en una sesión de la Academia de la Historia mereció alguna reseña en la prensa, como la siguiente, publicada en La Correspondencia de España: El Marqués de Cerralbo leyó un erudito informe sobre los descubrimientos arqueológicos hechos en la provincia de Pontevedra, y principalmente en Villagarcía de Arosa y sus inmediaciones, por D. J. Fernández Gil y Casal. (“Academia de la Historia”, La Correspondencia de España, 26 de febrero de 1915, pág. 5).
} 
castro, el de las parajinas [sic], que están al pie de él por el naciente, el nombre de Rubianes, Rubián, el nexo de D y A [signo] ${ }^{12}$ de la lápida ARI:, dedicada a Júpiter divino, encontrada cerca del lugar de Trabanca d'a Torre, y el nombre de Jovelle Joviales, no muy lejos del hallazgo, establecen una época de transición entre la dominación romana y sueva, que puede llamarse gótica en término general ${ }^{13}$.

En este párrafo figura la que se considera primera referencia impresa explícita al ara de Trabanca, aunque se trata de una mención parcial (limitada al texto de la primera línea, ARI:, y a un supuesto nexo DA) e indirecta, cuya función es servir como apoyatura, entre otras de carácter onomástico o arqueológico, para una datación en la época de transición entre la dominación romana y sueva.

En 1916, cuando Juan Fernández Gil y Casal da a la imprenta sus "Apuntes arqueológicos" han pasado ya doce años desde que vio la luz la primera referencia impresa -que conocemos- al ara de Trabanca, la realizada por García de la Riega en 1904. Pero a pesar del tiempo transcurrido, todavía no se había publicado ni el texto íntegro de la inscripción ni las características de su soporte.

Aún (y, repetimos, a tenor de lo que hemos podido averiguar) tendrían que transcurrir tres lustros hasta que Casto Sampedro le dedicó unos cuantos párrafos a una lápida que ya por entonces se consideraba perdida. Lo hizo en un breve artículo titulado "Aras romanas en el Museo de la Sociedad Arqueológica de Pontevedra" que el director de la Sociedad firmó en la ciudad del Lérez el día 13 de febrero de 1931, publicado aquel mismo año en el Libro de oro de la provincia de Pontevedra por José Cao Moure bajo el criptónimo PPKO.

El trabajo de Casto Sampedro ofrece una relación de aras votivas depositadas en el museo pontevedrés o de las que se tenía noticia en la institución; alude, entre aquellas, a las procedentes de la capilla de San Xulián de Requeixo (Cesures) donadas al Museo por el C. de la R. A. de la Historia en Villagarcía, D. Juan F. Gil y Casal y, a continuación, se refiere a la lápida de Trabanca en un largo epígrafe que copiamos íntegramente:

ARES. El mismo señor [Juan Fernández Gil y Casal] facilitó al Museo una hermosa copia de otra lápida, hoy desaparecida, aunque muy buscada, que se dedicó también al Marte griego. Fue descubierta por su señor padre y copiada cuidadosamente por su hijo.

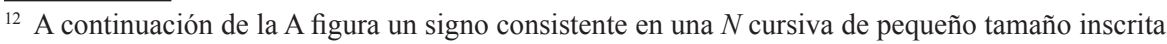
en la parte inferior izquierda de una $\mathrm{D}$ redonda sin trazo vertical.

${ }^{13}$ F. Fernández Gil y Casal, “Apuntes...”, págs. 42-44.
} 
El P. Fita creía ver en ella a un dios desconocido, uniendo como una sola las primeras palabras de la inscripción. Su mucho saber y el afán de ofrecer nuevos dioses a los estudiosos le habrán hecho cometer un error, a juicio del autor de estas lineas, consistente en no fijarse que a la palabra ARI siguen dos puntos que la aíslan de las siguientes que son: VL, vengador, epiteto de Marte; demonio o genio del lugar; y las del dedicante QVINTINO hijo de QVINTO con la fórmula general de V. S. L. M.

El original fue hallado en el sitio de la Torre, lugar de Trabanca Badiña, Carril, sobre la Estación, sirviendo de cubierta de una sepultura. No se pudo recoger aun a pesar de las muchas diligencias al efecto.

Esta supervivencia de la forma ARI en las orillas de la Ría de Arosa no dejará de interesar a los amantes de nuestra historia ${ }^{14}$.

Un lustro después de la todavía incompleta lectura de Casto Sampedro del ara de Trabanca, en 1936, se publicó el voluminoso tomo -más de un millar de páginas- correspondiente a la provincia de Pontevedra de la Geografía general del Reino de Galicia dirigida por F. Carreras Candi. El autor del libro, Gerardo Álvarez Limeses, menciona dos veces el ara de Trabanca, aunque sin describir ni las características del soporte ni el contenido de la inscripción; y al menos en una de las dos (si no en las dos) yerra al señalar al sujeto paciente del voto, pues una vez es Ares el Marte de los griegos y otra Júpiter.

La primera de las menciones de Álvarez Limeses al ara de Trabanca se halla en el capítulo dedicado al partido judicial de Cambados:

También hay aquí señales de influencia griega; no ya en el tipo de la mujer arosana, fantasía de que se han hecho eco varios escritores, sino en la toponimia de la comarca, abundante en palabras griegas y en algo más que palabras, como es la aparición en Trabanca, a un kilómetro de Villagarcía, de un ara dedicada al Marte de los griegos con una como caja de sepultura al pie $e^{15}$.

\footnotetext{
${ }^{14}$ Casto SAmpedro, "Aras romanas en el Museo de la Sociedad Arqueológica de Pontevedra" en José Cao Moure (ed.), Libro de oro de la provincia de Pontevedra, [Pontevedra], José Cao Moure (PPKO), 1931, pág. 33.

${ }^{15}$ Gerardo Álvarez Limeses, Geografia general del Reino de Galicia. Dirigida por F. Carreras Candi. Provincia de Pontevedra, Barcelona, Alberto Martín, 1936, pág. 416.
} 
La segunda, al referirse a la colección arqueológica reunida en su casa de Vilagarcía por Juan Fernández Gil y Casal:

Constituye este museo particular del Sr. Fernández Gil, a más de dichas tégulas [procedentes de las sepulturas del castro de San Cristóbal], algunas monedas de diferentes legiones romanas del tiempo de Galieno, Constantino el Grande y sus hijos, y restos de alfarería puzolana de Arezzo y de la llamada seguntina, así como aretes de cobre. Pero lo más interesante es el descubrimiento de un ara dedicada a Júpiter por un romano de la familia de los Quintinos que servía de cubierta a una sepultura cineraria. Por último, como elementos de épocas anteriores, posee también el señor Fernández Gil rascadores y hachas pulimentadas de piedra, un hacha de cobre, un puñal con vena central y otros productos de descubrimientos realizados también en Villagarcía o sus inmediaciones ${ }^{16}$.

Al margen de la dicotomía Marte-Júpiter, ambas citas ratifican el hallazgo de la lápida en Trabanca asociada a un enterramiento y la pertenencia del dedicante a la familia de los Quintinos. Además, en la segunda cita parece sugerirse que Fernández Gil conservaba esta pieza en su museo particular a pesar de que, como veremos, ya en 1909 el ara de Trabanca se consideraba perdida.

A comienzos de la década de los cincuenta, en 1953, Filgueira Valverde y García Alén publicaron el imprescindible esbozo de carta arqueológica de Pontevedra, ordenado por períodos históricos, titulado Materiales para la carta arqueológica de la provincia de Pontevedra. En el capítulo correspondiente a yacimientos romanos, y en la sección del Ayuntamiento de Villagarcía se recoge:

\begin{abstract}
Arealonga, Santa Eulalia de Afuera. Ara dedicada a Ares. Perdida o supuesta. Se la da como aparecida en el lugar de Trabanca da Torre, con una como caja de sepultura al pie. (Nota del P. Fita en nuestro Museo, Col. Sampedro, c. 71.- Álvarez Limeses, op. cit., 416 y 1020.- Fernández Gil y Casal, J. Apuntes arqueológicos, BRAG [i.e: BRAH] LXVIII, 1916) ${ }^{17}$.
\end{abstract}

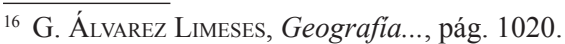

17 José Filgueira Valverde y Alfredo García Alén, Materiales para la carta arqueológica de la provincia de Pontevedra, Pontevedra, Museo de Pontevedra, 1953, pág. 166. Al año siguiente, 1954, se publicó esta obra como volumen octavo de El Museo de Pontevedra; en este caso la noticia del ara de Trabanca figura en la pág. 178.
} 
Y unas páginas más adelante, en el capítulo dedicado a los "Restos de baja romanidad, paleocristianos y suevos", se anota:

Arealonga, Santa Eulalia de Afuera. A un km. de Villagarcía, a la derecha del camino que va desde Trabanca da Torre al Xiabre, se halló "un sepulcro antropomorfo de tégulas" (sic) cubierto por un ara romana a Marte, en dirección E. a O. Dentro había algunos carbones, apareciendo también otros restos de tégulas. (Carta de D. Juan Fernández Gil y Casal, en 1905 ${ }^{18}$, a Sampedro y Folgar, Museo de Pontevedra, Col. Sampedro, C. 70) ${ }^{19}$.

Aunque los responsables de la carta arqueológica no vinculan ambas entradas, quizá por la duplicidad de nombres del dedicatario (Ares / Marte), parece evidente que las dos se refieren al mismo hallazgo, el ara de Trabanca.

De lo publicado en 1953 por Filgueira Valverde y García Alén acerca del ara de Trabanca, resulta particularmente interesante el recurso a una pareja de adjetivos ("perdida o supuesta"), el segundo de los cuales se revela determinante: por primera vez se cuestiona la existencia de una lápida de la que nadie podía ya dar testimonio fehaciente y que solo se conocía a través de referencias imprecisas e incompletas.

El mismo año que los autores de Materiales para la carta arqueológica de la provincia de Pontevedra destilaban una sombra de duda sobre la existencia real de la lápida de Trabanca, Fermín Bouza-Brey, sin duda convencido de su veracidad, la utilizaba como referente para modificar el nombre del dedicante del ara votiva a Neptuno aparecida en las inmediaciones del castro de Alobre el 2 de agosto de 1940, que Bouza-Brey en una primera lectura interpretaba como $Q(\text { uintus })^{20}$ pero que:

Agora [1957], como certa copia de un ara desaparecida feita por D. Xohán F. Xil e Casal nos arredores de Vilagarcía, logar de Trabanca da Torre, ten por adicente a un Quintinus, parécenos asisado

\footnotetext{
18 Aunque, como veremos, la carta no está fechada en 1905, sino en 1909.

19 J. Filgueira Valverde y A. García Alén, Materiales..., págs. 193-194.

${ }^{20}$ En 1940 Bouza Brey interpretaba la inscripción del ara de Neptuno del modo siguiente: “Neptun(i) Sac(rum). Q(uintus) C(elenus?) e(x) v(oto) l(ibens) p(osuit)" (Fermín BouZa BreY, "Nuevos epígrafes de la Galicia romana", Boletín de la Comisión Provincial de Monumentos Históricos y Artísticos de Orense, 249 (noviembre-diciembre de 1939), pág. 201).
} 
preferir iste prenomen ao de Quintus espresado, posto que parez foi corrente na terra ${ }^{21}$.

Dos años después, en 1955, José Filgueira Valverde y Álvaro D’Ors publicaron el fascículo de Inscripciones romanas de Galicia dedicado a las piezas del Museo de Pontevedra, fascículo en el que se catalogaban cuatro lápidas (núms. 15, 22, 35 y 36) procedentes de la capilla de San Julián de Requeixo (Cesures), donadas al museo pontevedrés por Juan Fernández Gil y Casal. Aunque una de estas cuatro lápidas (la núm. 22) ya no se encontraba entre los fondos del museo, Filgueira Valverde y Álvaro D'Ors la catalogaron, anotando: Se exhibió en las ruinas de Santo Domingo por lo menos hasta 1931; no fue hallada en las nuevas ordenaciones del Museo. No sabemos si fue devuelta al investigador que la entregó, si fue objeto de un intercambio o desapareció por otra causa que ignoramos ${ }^{22}$. El hecho de que el ara de Trabanca no solo no se catalogue, sino que ni siquiera se mencione (como sí se menciona y cataloga la de Requeixo, aun dándola por desaparecida a partir de 1931) parece indicar que nunca llegó a formar parte de los fondos del Museo de Pontevedra.

A partir de 1953 el olvido se cierne sobre el ara de Trabanca. Pasarán más de cuatro décadas hasta que Gemma Baños Rodríguez la incluya, con el número 127, en el Corpus de inscricións romanas de Galicia publicado en 1994. El contenido de la ficha catalográfica es el siguiente:

Inscrición votiva desaparecida. A primeira noticia que temos dela é de F. [sic] Fernández y Gil Casal [sic], que só transmite de xeito illado un nexo DA e ARI. C. Sampedro, o único que a viu, transmite soamente as palabras e letras illadas do texto pero non a súa disposición en liñas; non presenta aparato crítico nin estudio epigráfico. Encontrada en Trabanca da Torre, Arealonga (Vilagarcía de Arousa), utilizada como cuberta dunha sepultura. En 1953 os editores da Carta Arqueológica de Pontevedra dana xa como desaparecida ou inexistente. No Museo de Pontevedra consérvase

\footnotetext{
${ }^{21}$ Fermín Bouza Brey, "O castro de Alobre e os contactos antre a Bretaña e a Galiza na época romana" en Homaxe dos amigos e discípulos do petrucio da Prehistoria galega, Florentino L. A. Cuevillas, no LXX aniversario do seu nacimento, Vigo, Galaxia, 1957, pág. 105.

22 José Filgueira Valverde y Alvaro D'Ors: Inscripciones romanas de Galicia. III. Museo de Pontevedra, Santiago, CSIC - Instituto Padre Sarmiento, 1955, nº 22, pág. 43. Corresponde a la inscripción número 101 del Corpus de inscriciós romanas de Galicia. II. Provincia de Pontevedra, publicado por Gemma Baños Rodríguez en 1994.
} 
unha copia mecanografiada de orixe descoñecida, que difire do texto transmitido por Sampedro na primeira liña.

- Fernández y Gil Casal, BRAH 68, 1916, 44.

- Sampedro, Aras, 33. Filgueira \& García Alén, Carta Arqueológica, $166=$ EMP 8, 1954, 178 (só noticia do achado, sen lectura).

- Álvarez Limeses, Geografia, 1020.

$$
\begin{aligned}
& \text { AR }[\cdots] \\
& {[\cdots]} \\
& \text { ONIO } \\
& \text { Quin- } \\
& \text { tinus } \\
& \text { Q(uinti) f(ilius) v(otum) } \\
& \text { s(olvit) l(ibens) m(erito). }
\end{aligned}
$$

Se as tres primeiras liñas están ben transmitidas, na liña 1 podía empeza-lo nome da divinidade ou ben un texto na forma aram $\mathrm{p}$ (osuit). O nome do dedicante podía ser tamén un xentilicio que acabaría na liña 3, cun nominativo en -o. Sampedro, o único que a viu, le na liña 1: ARI VL separados claramente ${ }^{23}$.

Por primera vez se ofrece el texto -aunque incompleto- de la inscripción de Trabanca, con una división en líneas correcta a tenor de los dos dibujos de los que disponemos; quizá Gemma Baños tomó la lectura del epígrafe de esa copia mecanografiada de orixe descoñecida que cita como conservada en el Museo de Pontevedra, y que no hemos podido localizar.

En 1996, a raíz de la publicación del catálogo de inscripciones romanas de Pontevedra, José María Blázquez proponía un giro importante en la interpretación de las primeras líneas del epígrafe de Trabanca; ya no eran ni el griego Ares ni el romano Júpiter los dioses a los que Quintinus ofreció su voto, sino un dios indígena que J. M. Blázquez incluyó en la relación de deidades autóctonas: En la actual provincia de Pontevedra han aparecido otros teónimos indígenas [...] que son los siguientes: [...] AR[‥] de Trabanca da Torre, Arealonga (Villagarcía de Arosa), ara consagrada por Quintianus ${ }^{24}$.

\footnotetext{
${ }^{23}$ Gemma Baños Rodríguez, Corpus de inscricións romanas de Galicia. II. Provincia de Pontevedra, Santiago, Consello da Cultura Galega, 1994, núm. 127, pág. 303.

${ }^{24}$ José María BlÁzquez Martínez, "Religiones indígenas en la Hispania romana (addenda et corrigenda)”, Gerión, 14 (1996), pág. 353.
} 
Desde ese ya lejano año de 1996 han transcurrido casi dos décadas y no se ha vuelto a mencionar el monumento epigráfico hallado un siglo antes en Trabanca. Quizá los documentos que ofrecemos a continuación exciten el interés de algún investigador para realizar nuevas pesquisas en busca del ara de Trabanca.

\section{Las cartas y dibujos de JuAn Fernández Gil y Casal}

A los testimonios publicados acerca del ara de Trabanca que relacionamos en el capítulo anterior pueden sumarse cinco documentos -cuatro de ellos inéditosdebidos a Juan Fernández Gil y Casal, a los que nos referiremos a continuación: tres cartas (una a López Ferreiro y dos a Casto Sampedro) y dos dibujos (el que conserva la Real Academia Galega y la aguada del Museo de Pontevedra).

\section{Carta de Fernández Gil a López Ferreiro (8 de mayo de 1909)}

En una caja de papeles pendientes de catalogación que forma parte del legado de Ricardo Blanco-Cicerón depositado en el Museo do Pobo Galego se conserva una carta ${ }^{25}$, fechada en Vilagarcía de Arousa el 8 de mayo de 1909, que Juan Fernández Gil y Casal escribió a Antonio López Ferreiro para consultarle algunas cuestiones relacionadas con la Exposición Regional Gallega, certamen que en aquellos momentos se preparaba en Santiago y de cuya Sección Arqueológica era presidente el historiador compostelano.

No debe sorprender que la misiva forme parte de un fondo documental ajeno tanto al remitente como al destinatario, puesto que Ricardo Blanco Cicerón era vicepresidente de la Sección Arqueológica ${ }^{26}$ y uno de los gestores de la documentación tocante al evento que se organizaba; y puesto que esta carta-aunque personal- hacía referencia a la organización de la exposición programada para el mes de julio, no resulta extraño que López Ferreiro la entregara a Blanco Cicerón.

La misiva - manuscrita, fechada y firmada por Fernández Gil- ocupa tres carillas de un pliego de papel blanco en cuarto, y en ella se hace referencia a tres asuntos: la correcta interpretación de una inscripción romana de la que Fernández Gil preparaba una lámina para exponer en la Sección Arqueológica de la Exposición, la remisión adjunta de un listado y la pertinencia, de cara a la Exposición de Santiago, de lo contenido en una relación enviada previamente; la mención a

\footnotetext{
${ }_{25}$ Puede verse la transcripción íntegra de esta carta en el Apéndice I, núm. 1.

${ }^{26}$ Además de Ricardo Blanco-Cicerón, Salvador Cabeza de León y Antonio García Vázquez-Queipo desempeñaban la tricéfala vicepresidencia de la Exposición Regional Gallega.
} 
estos dos últimos asuntos, de manera tangencial y sin explicitarlos, pone de manifiesto que eran suficientemente conocidos por el receptor, posiblemente como producto de un intercambio epistolar previo. En cualquier caso ambos asuntos son secundarios, ya que la intención fundamental de Fernández Gil al escribir esta misiva es la de consultar con López Ferreiro la interpretación del epígrafe latino de la denominada lápida de Trabanca, lápida de Ares o de Ari, pues de los tres modos se la cita.

En el primer párrafo de la carta, inmediatamente después de la dirección y el afectuoso saludo, el remitente da cuenta a López Ferreiro de su pretensión: $A l$ terminar una aguada-dibujo de la lápida Ari de que di a V. cuenta hace tiempo y que hoy reproduzco para la exposición ocurrióseme intentar una vez más su interpretación, y habiendo llegado a esta se la consulto. Ara a Júpiter (según el P. Fita), o a Ares, según Casto Sampedro y el muy intransigente Lariega [i.e: la Riega]. Estas primeras líneas ofrecen información relevante acerca del ara:

a. Fernández Gil comunicó tiempo atrás a López Ferreiro la existencia del ara acerca de la que le envía, en esta ocasión, una consulta.

b. El remitente acaba de terminar una aguada-dibujo de la lápida [...] para la exposición. Es evidente -en mayo de 1909 y con las alusiones que figuran a continuación- que el genérico sintagma la exposición se refiere a la Exposición Regional Gallega de 1909, en cuya Sección Arqueológica se expondrían varios millares de piezas originales, pero también dibujos o fotografías de aquellas otras que no pudieran trasladarse al compostelano colegio de San Clemente, sede de la Sección. A tenor de las relaciones de piezas expuestas en la muestra que hemos hallado, el ara de Trabanca no se llevó al certamen compostelano en el que figuró, en su lugar, la aguada-dibujo (a la que en adelante denominaremos aguada) realizada por Fernández Gil y Casal, que se conserva actualmente en el Museo de Pontevedra, y a la que nos referiremos en el epígrafe tercero.

c. Al tiempo que bosquejaba la aguada del ara de Trabanca para la Exposición, Fernández Gil intentó descifrar una vez más (lo que revela ensayos anteriores) la inscripción; pero la interpretación de las primeras líneas no resultaba sencilla, como ponían de manifiesto las divergencias en la lectura del P. Fita (para quien el voto se dedicaba a Júpiter) y en las de Casto Sampedro y García de la Riega (quienes estimaban que se ofrecía a Ares). En busca de una nueva opinión, Fernández Gil recurre a la potestad epigráfica de López Ferreiro, al que comunica las conjeturas de su lectura y su interpretación: 


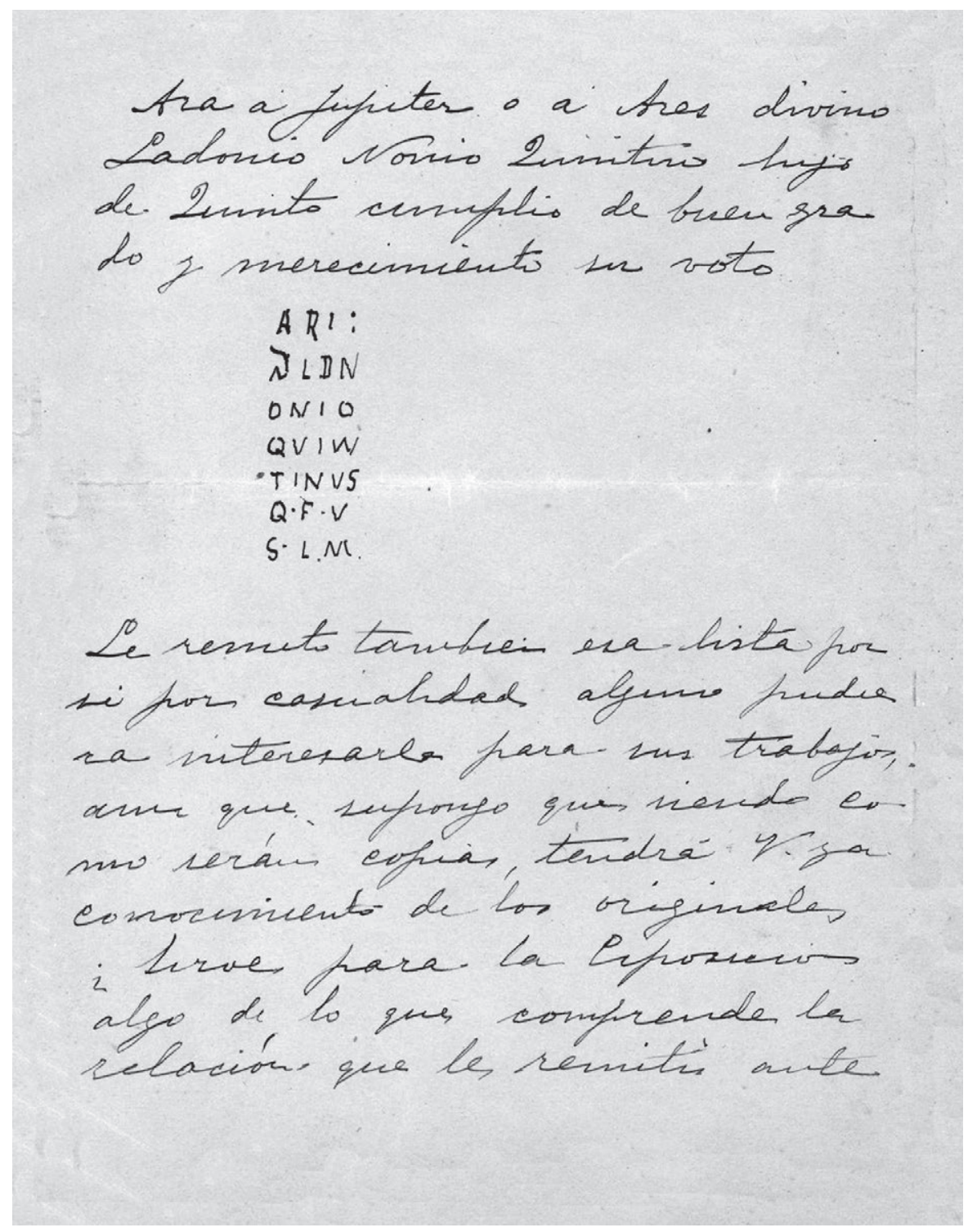

Lámina 1. Copia del epígrafe del ara de Trabanca según figura en la carta enviada por Juan Fernández Gil y Casal a Antonio López Ferreiro el 8 de mayo de 1909.

(Museo do Pobo Galego, F. Blanco Cicerón, pendiente de catalogación, s.n., h. 1v.). 
A R I:

$$
\begin{aligned}
& {\left[\text { signo }^{27}\right] L D N} \\
& O N I O \\
& Q V I W^{28} \\
& T I N V S \\
& Q \cdot F \cdot V \\
& S \cdot L \cdot M
\end{aligned}
$$

Ara a Júpiter o a Ares divino. Ladonio Nonio Quintino, hijo de Quinto, cumplió de buen grado y merecimiento su voto.

\section{Dibujo de la Real Academia Galega}

Entre los papeles que componen el fondo donado a la Real Academia Galega por la familia de Eladio Oviedo Arce en 1918 figura una cuartilla de papel con dos dibujos del ara de Trabanca y otros tres del sepulcro al que apareció asociada ${ }^{29}$. Estos dibujos, especialmente los dos del bloque inscrito, resultan de una importancia capital para conocer tanto la morfología como el epígrafe de un ara que ya en el año 1909 se consideraba desaparecida, y de la que no se conservan más imágenes -además de la que nos ocupa-que la aguada depositada en el Museo de Pontevedra, de mayor tamaño pero de menor entidad informativa.

El soporte de estos cinco dibujos es una cuartilla de papel blanco envejecido, de 205x128 mm, que presenta algunos desperfectos en la mitad superior, especialmente en la zona del ángulo izquierdo, maculado por un grupo de manchas tostadas. Tanto los cinco dibujos como el título, el rótulo y la firma se realizaron utilizando un lápiz graso que, en los dibujos, sirvió para delinear las figuras y para proporcionar volumen mediante rayados o sombreados.

Una primera ojeada a esta lámina, permite dividirla visualmente en cinco campos:

\footnotetext{
${ }^{27}$ El signo que aparece en esta formado por un pequeño - la mitad de la altura el resto de las letrasángulo de $45^{\circ}$ con el vértice hacia arriba, de cuya parte inferior derecha arranca una línea que se incurva, formando un arco a la derecha del ángulo que lo rebasa por la parte superior. Según el informe que Fernández Gil envió en 1915 a la Real Academia de la Historia, este signo correspondía al nexo latino DA (RAH, CAPO/9/7967/07(2), f. 10v y F. Fernández Gil y CASAL, “Apuntes...”, pág. 44). ${ }^{28}$ Aunque, según la lectura, se trata de la N postnuclear de la primera sílaba, Fernández Gil traza en esta posición una $\mathrm{W}$.

${ }^{29}$ RAG, Fondo Oviedo Arce, caixa 125, carp. no 5, s.n. Véase Lám. II. Parece probable que una carta o algún tipo de nota -que no se conserva- acompañara a esta cuartilla, escrito que sería quizá un excelente documento no solo para certificar quien era su destinatario original -quizá el reputado epigrafista que era Oviedo Arce-, sino para conocer alguna circunstancia más del hallazgo o de las características del monumento.
} 


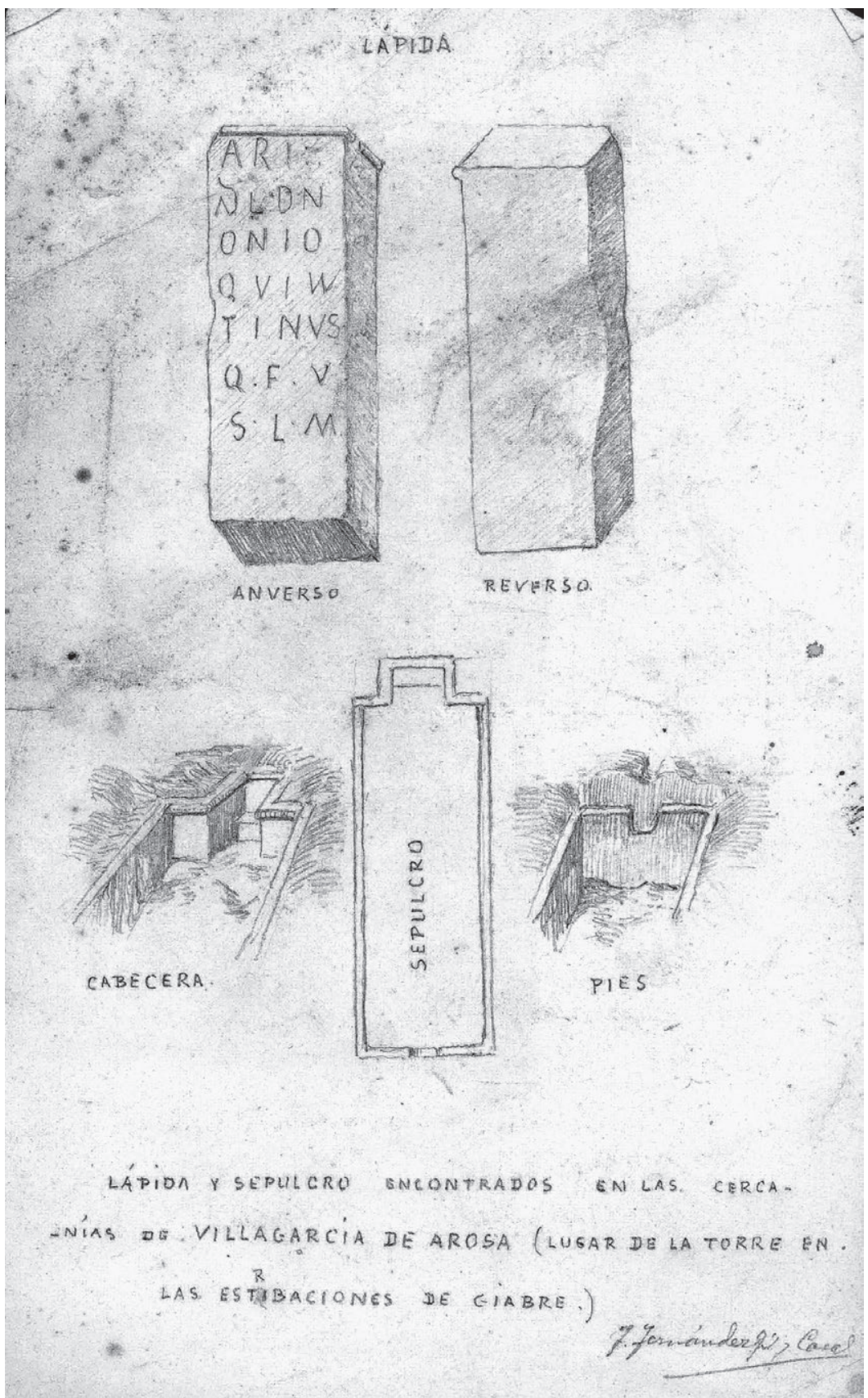

Lámina 2. Ara de Trabanca y sepulcro al que apareció asociada, según Juan Fernández Gil y Casal. (Real Academia Galega, F. Oviedo Arce, caixa 125, carp. núm. 5, s.n.). 
1. En cabecera y centrado, un rótulo en mayúsculas: LÁPIDA.

2. Dos dibujos en batería que representan dos perspectivas del paralelepípedo que sirvió como soporte a la inscripción de Trabanca, y que ofrecen la vista de sus seis caras: el primer dibujo, rotulado ANVERSO, presenta una perspectiva fronto-laterosiniestra-inferior; el segundo, rotulado REVERSO, dorso-laterodiestra-superior ${ }^{30}$.

3. Tres dibujos en batería: el central presenta una vista cenital de la sepultura de Trabanca, mientras que los dos laterales ofrecen el detalle de la cabecera y los pies de dicho sepulcro. Cada uno de estos dibujos lleva su correspondiente rótulo en mayúsculas: CABECERA, SEPULCRO y PIES.

4. En la parte inferior de la cuartilla, un rotulo en mayúsculas localiza espacialmente el lugar del hallazgo de la lápida y el sepulcro: LÁPIDA Y SEPULCRO ENCONTRADOS EN LAS CERCANÍAS DE VILLAGARCÍA DE AROSA (LUGAR DE LA TORRE, EN LAS EST ${ }^{\mathrm{R}}{ }^{\mathrm{IBACIONES}}{ }^{31}$ DE GIABRE).

5. Firma autógrafa de J. Fernández Gil y Casal en el ángulo inferior izquierdo.

Sin duda lo más interesante de esta lámina es la representación de las seis caras del ara de Trabanca mediante dos dibujos en batería que muestran el monumento como un paralelepípedo rectángulo de base cuadrangular cuya altura guarda una proporción de 3:1 respecto a los lados de la base, ofreciendo la imagen de un sillar de aristas rectas y perfectamente escuadrado. Solo una moldura convexa de sección semicircular como remate superior del plano frontal y el izquierdo interrumpe la perfecta regularidad morfológica de este bloque, posiblemente granítico.

A tenor de lo que revelan los dibujos de Fernández Gil, las caras superior e inferior del monumento eran totalmente planas, sin que se observe rebaje alguno (a modo de hincón) en la parte inferior, ni tampoco resaltes que denoten la presencia de foculus o pulvini en la superior. A excepción del epígrafe insculturado en la cara frontal y de la moldura semicircular que remata esta misma cara y la izquierda, el resto, las cuatro caras mayores (frontal, laterales y dorsal), son planas.

El estado de conservación del ara, cuando se dibujó, era bueno: faltaba solo el vértice superior derecho y un pequeño tramo de la moldura que remataba la cara izquierda. Presentaba, además, un pequeño rebaje en la parte media de la arista anterior derecha, y otro rebaje mucho más acusado a la misma altura de la arista posterior izquierda; este rebaje -quizá debido a un pulimentado intenso-ocasionó un rehundimiento que afectó a un tercio de esta arista y de una parte del tramo medio de las caras derecha y posterior.

\footnotetext{
${ }^{30}$ En adelante, para referirnos a cada una de las caras del ara, utilizaremos como referencia de orientación la cara que presenta la inscripción, en posición de lectura, a la que denominaremos frontal.

${ }^{31}$ La letra $R$ de ESTRIBACIONES se añadió posteriormente, superponiéndola entre a $T$ y la $I$.
} 


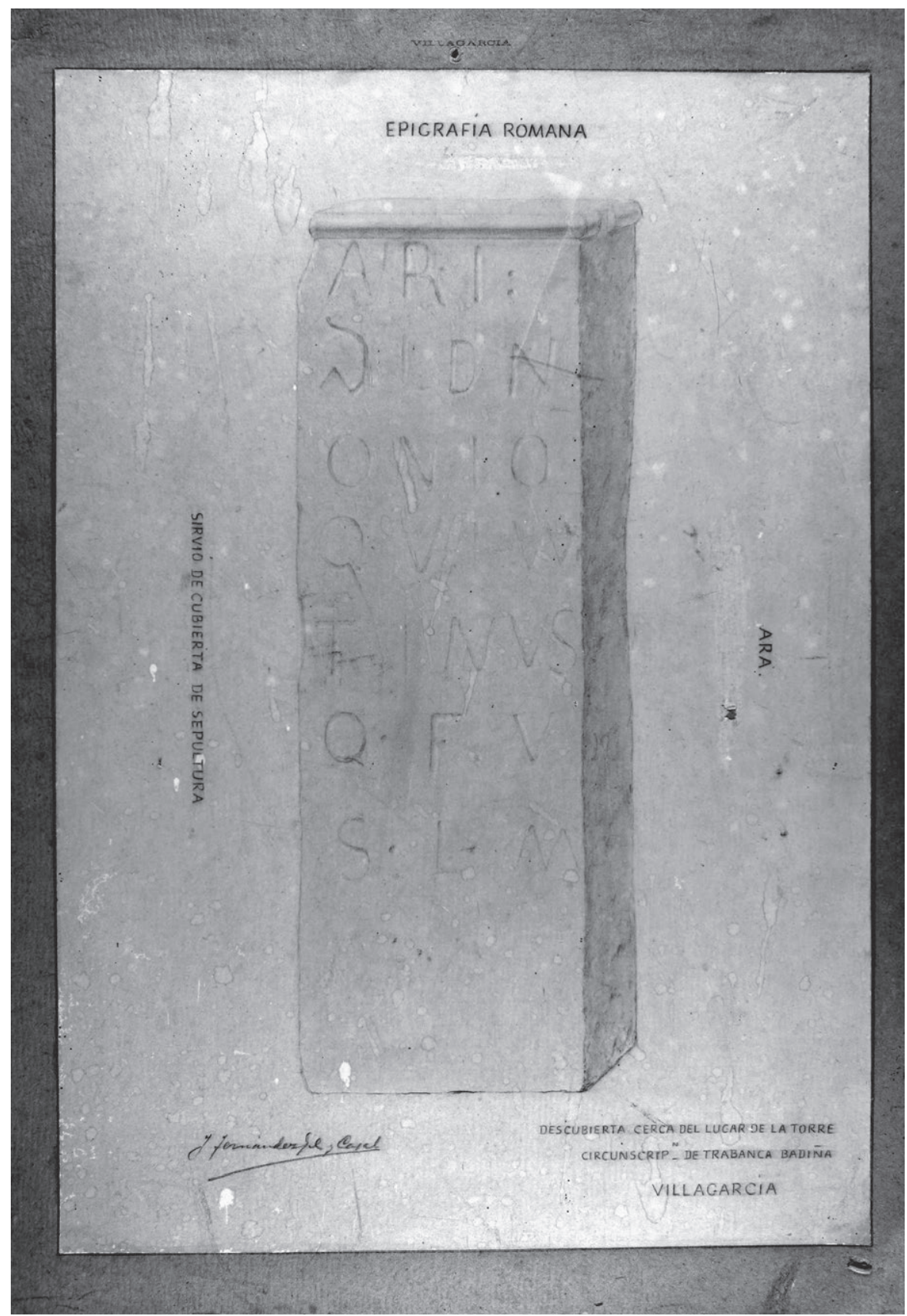

Lámina 3. Ara de Trabanca según el dibujo enviado por Juan Fernández Gil y Casal a la Exposición Regional Gallega de 1909. (Museo de Pontevedra, S/R 001305). 
Por lo que se aprecia en el dibujo, la que hemos denominado cara anterior presentaba una inscripción de siete líneas en letras capitales de correcta ejecución que coincide, en lo que al texto se refiere, con la transcripción que Fernández Gil envió a López Ferreiro en mayo de 1909. Pero la lámina conservada en la Real Academia Galega proporciona una visión más correcta de la distribución de las letras en el campo epigráfico, especialmente en la primera línea en la que, en el dibujo, se percibe un espacio a continuación de los dos puntos que sin duda correspondería a una (o más) letras perdidas, cuyos vestigios podrían ser esos dos puntos superpuestos que representó el transcriptor. Por lo tanto parece conveniente rectificar la primera línea de la lectura que Fernández Gil remitió en 1909 a López Ferreiro, transformándola en: ARI $[\cdots]$

El resto del epígrafe copiado por Fernández Gil en el dibujo coincide con la transcripción que figura en la carta, puesto que la única diferencia destacable es el último signo de interpunción (entre la L y la M) que en la carta figura un poco más bajo, al pie de la primera letra.

Pero el interés de esta lámina no reside exclusivamente en proporcionar una imagen del ara y del texto epigrafiado, sino que ofrece también la representación de la sepultura a la que el ara de Trabanca sirvió de cubierta. Como revelan los tres dibujos que figuran en el tercer campo, se trata de una sepultura de inhumación rectangular con cabecera diferenciada igualmente rectangular (aunque difiere la relación longitud/anchura en los dos dibujos que la representan), en cuya mitad superior aparece un resalte con función de soporte occipital del difunto, mientras que en el pie muestra un rebaje semicircular.

Aparentemente se trata de un sepulcro monolítico, puesto que se advierte una continuidad y regularidad en sus paredes que no concuerda con los sepulcros construidos mediante tégulas o losas de piedra.

En esta lámina no figura referencia alguna ni a la orientación ni al tipo de cubierta que cerraba el sepulcro; tampoco al hallazgo, en su interior, de restos humanos o de ajuar.

\section{Aguada del Museo de Pontevedra}

En el Museo de Pontevedra ${ }^{32}$ se conserva una aguada del ara de Trabanca firmada por Juan Fernández Gil y Casal que si bien no ofrece novedades acerca de la morfología y el epígrafe que refleja el dibujo custodiado en la Real Academia Galega, sirve para testimoniar la presencia del monumento trabanquino -aunque no de la pieza original- en la Exposición Regional Gallega de 1909.

\footnotetext{
${ }_{32}$ Museo de Pontevedra, S/R 001305. Véase Lám. III.
} 
Se trata de un dibujo a lápiz, coloreado a la aguada, que se realizó sobre un pliego de papel de 56 x 38'5 cm y que -destinado a formar parte de la sección epigráfica del certamen compostelano de 1909- se montó, adhiriéndolo, sobre una lámina de madera de $65^{\prime} 3$ x $48^{\prime} 7 \mathrm{~cm}$.

Aunque la finalidad de este dibujo (mostrar el ara de Trabanca a los visitantes de la Sección Arqueológica de la Exposición Regional Gallega) justifica un mayor cuidado en su ejecución, coloreado incluido, la información que proporciona acerca del soporte epigráfico es menor que la que se recoge en el dibujo conservado en el archivo de la Real Academia Galega, puesto que la del museo pontevedrés ofrece solo una vista frontal del ara y de su proyección superior y lateral izquierda, hurtando al espectador las características -si bien poco relevantes- de la cara dorsal, inferior y laterodiestra del monumento trabanquino. En cuanto a la representación del epígrafe en la aguada, resulta prácticamente idéntica a la del dibujo, con la única diferencia del signo de interpunción entre la L y la m de la última línea que, en la aguada, está (suponemos, de acuerdo a los cánones de la epigrafía latina) correctamente situado a la mitad de la altura de las letras.

La aguada que se conserva en el Museo de Pontevedra, encabezada por el topónimo VILLAGARCÍA, presenta alrededor del dibujo cuatro leyendas rotuladas que concuerdan con la finalidad expositiva para la que fue concebida: EPIGRAFÍA ROMANA (parte superior), ARA (lateral derecho), SIRVIÓ DE CUBIERTA DE SEPULTURA (lateral izquierdo) y DESCUBIERTA CERCA DEL LUGAR DE LA TORRE / CIRCUNSCRIP NE TRABANCA BADIÑA / VILLAGARCÍA (inferior izquierda). Además, en la zona inferior izquierda presenta la firma del autor: Juan Fernández Gil y Casal.

Estos rótulos, el tamaño de la lámina, su cuidada realización y el montaje sobre madera revelan la finalidad expositiva de la aguada y se ajustan a la aseveración que figura en las primeras líneas de la carta suscrita por Fernández Gil a López Ferreiro el 8 de mayo de 1909: Al terminar una aguada-dibujo de la lápida Ari [...] que hoy reproduzco para la exposición. Sin duda el dibujo a la aguada firmado por J. Fernández Gil y Casal que se conserva en el Museo de Pontevedra se corresponde con el que el remitente de la carta mencionaba en su misiva, y por lo tanto cabe datar esta aguada en Vilagarcía de Arousa durante los primeros días de mayo de 1909.

Según consta en una relación manuscrita de objetos destinados a la Exposición Regional Gallega de 1909, Juan Fernández Gil envió algunas piezas de su propiedad para que se expusieran en el certamen compostelano; entre ellas:

- Una arma de bronce de las llamadas acha [sic] de asas. [Expositor:] D. J. Fernández Gil Casal. Villagarcía Pontevedra. [...] 
- Sepulcro romano. D. J. Fernández Gil Casal. Villagarcía Pontevedra. [...]

- Una lámina copia del Meadelo.

- Lámina copia de las esculturas de Ballotes. D. J. Fernández Gil Casal. Villagarcía Pontevedra. [...]

- Una idem [pesa de piedra] mediana. D. J. Fernández Gil Casal. Villagarcía ${ }^{33}$.

Las láminas copia del Meadelo y de Ballotes corresponden a sendas estaciones de arte rupestre de la parroquia de Bamio (Vilagarcía de Arousa) que, por su condición, no podían trasladarse a la muestra compostelana; para solventar esta imposibilidad, Fernández Gil realizó un par de láminas que reproducían los petroglifos vilagarcianos ${ }^{34}$.

¿Por qué Fernández Gil pintó la aguada del ara de Trabanca para la Sección Arqueológica de la Exposición Regional Gallega de 1909 en lugar de llevarse al certamen el monumento original? No cabe responder a esta pregunta argumentando dificultades para el traslado del bloque pétreo puesto que, aunque no conocemos sus dimensiones, no sería más pesado que, por ejemplo, el que servía como soporte a la lápida de Araño que figuró en la muestra compostelana ${ }^{35} ; \mathrm{y}$, en cualquier caso las complicaciones de movilidad derivadas de su volumen serían considerablemente más reducidas que las que debió de suponer el traslado del grupo escultórico de Minerva que se llevó hasta el centro del patio del colegio de San Clemente, sede de la exposición.

Cabe manejar otras dos conjeturas para explicar que en la exposición compostelana no figurara el original del monumento trabanquino, sustituido por un dibujo a la aguada: o el propietario del ara se negó a prestarla, o la pieza ya había desaparecido de donde quiera que se conservaba desde su hallazgo. Esta segunda es la hipótesis que nos parece más probable a la vista de un documento que, aun sin fecha, cabe datar en las primeras semanas de la primavera de 1909.

\footnotetext{
${ }^{33}$ Museo do Pobo Galego, Fondo Blanco-Cicerón, pendiente de catalogación.

${ }^{34}$ En los "Apuntes arqueológicos" de Fernández Gil se incluyen dos láminas con su firma que reproducen los petroglifos de Os Ballotes y Meadelo (F. Fernández Gil y CASAL, "Apuntes...", págs. 34 y 35 ).

${ }^{35}$ Sobre el hallazgo, características y peripecias mercantiles de la monumental estela de Araño (Rianxo), adquirida por la Sociedad Arqueológica de Pontevedra en enero de 1909 y trasladada -a pesar de su volumen- a la Exposición Regional Gallega, puede verse: Carlos Santos FernándeZ, "Correspondencia sobre la estela romana de Araño (Rianxo) conservada en el Museo de Pontevedra", Cuadernos de Estudios Gallegos, 61 (2014), págs. 319-374.
} 
El documento al que nos referimos se conserva en el Museo do Pobo Galego. Se trata de doce cuartillas manuscritas por una cara y encabezadas por un sello de tampón en tinta roja con la leyenda VILLAGARCÍA, sin título ni indicación alguna y que, aunque caligráficamente no pueden atribuirse a Juan Fernández Gil y Casal, coinciden, en cuanto al contenido, tanto con las tesis históricas y filológicas expresadas por el escritor de Vilagarcía como con algunos de los materiales que integraban su colección y los descubrimientos realizados por él.

Estas doce hojas ofrecen una relación de monumentos -en el más amplio sentido de la palabra: muebles, inmuebles e inmateriales- del entorno de Vilagarcía, quizá aquellos cuyos originales, dibujos o fotografías -entendía el recolector- podrían exhibirse en la Exposición Regional Gallega. Tal vez es esta la relación a la que se refiere el último párrafo de la carta de Fernández Gil a López Ferreiro: ¿Sirve para la Exposición algo de lo que comprende la relación que le remití anteriormente? ¿Qué se remite de todo ello?. Esta hipótesis es la que permite datar la heterogénea relación antes del 8 de mayo de 1909, fecha de la misiva de Fernández Gil a López Ferreiro. Y es en esa relación en la que se anota, acerca del ara de Trabanca: Bosquejo de una ara dedicada a Júpiter según el P. Fidel Fita y a Marte según Larriega (a Júpiter cremos [sic]), original perdido ${ }^{36}$. Ese bosquejo es la aguada del ara de Trabanca que Fernández Gil pintó para la Exposición Regional Gallega; y que pintó, según se indica en el último sintagma (original perdido), porque el ara ya había desaparecido.

Es posible, pues -si las anteriores conjeturas no son erróneas-, que antes de mayo de 1909 se hubiera perdido ya la pista del ara de Trabanca, pérdida que movió a Fernández Gil a enviar al certamen compostelano la aguada de una inscripción de la que, desde entonces, no se ha vuelto a tener noticia.

\section{Carta de Fernández Gil a Casto Sampedro (19 de mayo de 1909)}

Once días después de remitir el pliego dirigido a López Ferreiro acerca del ara de Trabanca, Juan Fernández Gil y Casal escribió otra misiva sobre el mismo asunto a Casto Sampedro.

La carta al presidente de la Sociedad Arqueológica de Pontevedra, fechada en Vilagarcía de Arousa el 19 de mayo de $1909^{37}$, comienza con un extenso

\footnotetext{
${ }^{36}$ Museo do Pobo Galego: Fondo Blanco-Cicerón, pendiente de catalogación

${ }^{37}$ Puede verse la transcripción íntegra de esta carta en el Apéndice I, núm. 2. Al referirse a esta carta, Filgueira Valverde y García Alén cometieron un error de lectura que los llevó a retrotraer su redacción a 1905: "Carta de D. Juan Fernández Gil y Casal, en 1905, a Sampedro y Folgar, Museo de Pontevedra, Col. Sampedro, C.70)" (J. Filgueira Valverde y A. García Alén, Materiales..., pág. 194). No puede sorprender la confusión de los investigadores pontevedreses, puesto que la minúscula caligrafía de Fernández Gil y los inacabados rasgos de algunos de sus numerales dificultan, a veces
} 
párrafo en el que se alude a una epístola anterior de Casto Sampedro a Fernández Gil sobre el ara de Trabanca, a la correspondencia -que no hemos podido localizar- entre el presidente de la Arqueológica teucrina y el padre Fita acerca del monumento epigráfico, y a la onomástica del lugar en el que se halló el ara, pues Fernández Gil estima que el topónimo adecuado es Trabanca Badiña-que denomina a una porción de territorio de Trabanca- y que tiene su correlato en Trabanca Sardiñeira.

Tras un par de divagaciones etimológicas - a las que tan aficionado era el remitente-, Fernández Gil retoma es asunto del ara de Trabanca con un contundente Volvamos a la lápida. Pero la vuelta se reduce a un dibujo y a una serie de lacónicas anotaciones, sin duda elocuentes para el destinatario de la carta, aunque no tanto para quienes hemos de interpretarlas en un documento descontextualizado.

El dibujo, inscribible en un rectángulo de 90 x $115 \mathrm{~mm}$, representa el sepulcro sobre el que se halló el ara de Trabanca, orientado y localizado respecto al camino al monte Xiabre desde el lugar de la Torre. Tomado desde un plano superior situado en el ángulo inferior derecho de la sepultura, este dibujo resulta bastante más sencillo - un mero esbozo, aunque bien trazado-que los que ofrece la lámina de la colección Oviedo Arce a la que nos hemos referido en el epígrafe anterior, pero resulta evidente la identidad del objeto representado y de la mano que lo trazó.

El boceto representa una sepultura de inhumación rectangular con cabecera diferenciada también rectangular, en cuya mitad superior aparece un poyete que serviría como soporte occipital; además, en el centro de la parte inferior se aprecia un pequeño rebaje semicircular. Aparentemente se trata de un sepulcro monolítico, puesto que se advierte una continuidad y regularidad en sus paredes que no concuerda - a pesar de lo que se afirma en las notas complementarias-con los sepulcros construidos mediante tégulas o losas de piedra.

Dos símbolos, E y O, sobre la cabecera y bajo el rebaje semicircular respectivamente, representan la orientación E-O del sepulcro; asimismo, a los pies de la sepultura e inmediatas al símbolo de poniente, un par de líneas paralelas representan un camino, según la leyenda rotulada entre ambas líneas: Camino que desde el lugar de la Torre conduce al monte Xiabre.

Como complemento de este boceto figuran seis breves anotaciones:

a. Formado con tejones gruesos y lastras, cubriendo el ara una parte de él y estando el resto cubierto con lastras. A pesar de esta afirmación, ni en el dibujo conservado en la Real Academia Galega ni en el boceto del Museo de Pontevedra se aprecia discontinuidad alguna en las paredes del sepulcro, por lo que, a primera vista, parece ser una tumba monolítica. En cualquier caso suponemos que Fernández Gil no se preocupó en representar 
las tégulas o lastras de piedra que formaban las paredes del sepulcro, pero parece evidente - a tenor de la información verbal- que existían.

b. Deposito en él: tierra negra.

c. Dirección: la que se indica E a $O$.

d. Fecha: del 1885 al 1890. Sin duda esta es la información más relevante de la carta, que posiblemente (¿a qué, si no?) alude al momento del hallazgo del sepulcro y del ara asociada: entre 1885 y 1890, retrotrayendo en más de una década su descubrimiento a la primera noticia impresa que conocemos. No puede dejar de sorprender la imprecisión de Fernández Gil respecto a la fecha del hallazgo - que ubica cronológicamente en un arco de cinco años- si tenemos en cuenta que "fue descubierta por su señor padre"38 cuando Fernández Gil (nacido en 1863) tenía entre 22 y 27 años.

e. En el mismo terreno se encontraron restos de tégulas en una extensión regular.

f. Supongo no se olvidará de mi encargo, ni de decirme la opinión del docto jesuita [el P. Fita] sobre la interpretación referente a la piedra. El recurso al padre Fita a través de Casto Sampedro, para descifrar la inscripción del ara, al igual que la carta al López Ferreiro del 8 de mayo, con la misma finalidad, revelan que Juan Fernández Gil trataba de hallar -en aquellos días de mayo previos a la Exposición Regional Gallega de 1909- una interpretación correcta del epígrafe, destinada posiblemente a complementar la aguada que se conserva en el Museo de Pontevedra.

Y, como cierre de la carta - precediendo a la despedida- otro párrafo sobre la Exposición Regional Gallega: en este caso acerca de la persona un tal Limia, a quien López Ferreiro encomendó fotografiar los vestigios histórico-artísticos de Arousa acompañando a Fernández Gil en un recorrido por lo que este consideraba su pequeña provincia.

\footnotetext{
sobremanera, la interpretación de los manuscritos del investigador vilagarciano. En cualquier caso -y aunque el último número de la data de esta carta bien podría leerse como un 5 o como un 9 (1905 o 1909)-, un párrafo del texto permite fecharla correctamente: ¿Quién va a esa a fotografiar lo fotografiable para la Exposición? A esta mi pequeña provincia me dijo Ferreiro mandará a un tal Limia, sacerdote, y en comisión de 2 la recorreremos. La Exposición es la Exposición Regional Gallega de 1909, Ferreiro es Antonio López Ferreiro, presidente de la Sección Arqueológica del certamen, y Limia es el presbítero José Limia Rodríguez, habitual colaborador de López Ferreiro en labores fotográficas. Resulta evidente que el párrafo se refiere a la preparación de la exposición compostelana de 1909, y por lo tanto no cabe duda de que 1909 es el año en el que se escribió esta carta.

${ }^{38}$ C. SAmpedro, “Aras...”, pág. 33.
} 


\section{Carta de Fernández Gil a Casto Sampedro (8 de marzo de 1917)}

Casi ocho años después de la carta anterior, el ara de Trabanca volvió a ser objeto de la correspondencia cruzada entre Juan Fernández Gil y Casto Sampedro, como revela un pliego firmado por el primero que se conserva en el Museo de Pontevedra.

Del tenor de esta carta, fechada en Vilagarcía el 8 de marzo de $1917^{39}$, se deduce que sirve como respuesta a una misiva de Casto Sampedro al investigador vilagarciano solicitando información acerca de las circunstancias en las que se halló el ara de Trabanca y de la fidelidad que, respecto del original, guardaba un dibujo - quizá la aguada destinada a Exposición Regional Gallega- remitido por Fernández Gil. Se trata pues de una demanda de información parcial: el presidente de la Sociedad Arqueológica de Pontevedra no necesita datos de las características externas del ara-se los proporciona el dibujo que maneja-, ni del texto insculturado, ni de su lectura o interpretación; le basta con obtener noticias de la ubicación y el contexto arqueológico en que se halló el ara de Trabanca, y con confirmar si el dibujo de que dispone guarda proporción escalar con el desaparecido monumento epigráfico.

La respuesta de Fernández Gil se centra, pues, en esos asuntos. Acerca de la fidelidad del dibujo, dice que lo realizó mediante cuadrículas a partir de un primer boceto tomado del natural que copió, afirma, con la conciencia que acostumbro a poner en todas mis cosas; solo el tamaño de las letras -continúa-podría diferir levemente (algún milímetro) de la proporción de las originales. De este modo, Fernández Gil confirma a Casto Sampedro que, a falta del perdido monumento trabanquino, puede fiarse de las dimensiones que proporciona en su dibujo. Y por otra parte parece dar a entender que el dibujo a que se hace referencia, sin duda la aguada destinada a la Exposición Regional Gallega, lo realizo a escala 1:1, por lo que cabe especular con la posibilidad de que las dimensiones reales del ara -si tomamos la aguada como referente- fueran $42 \mathrm{~cm}$ de alto y $14 \mathrm{~cm}$ de ancho.

Si esta (arriesgada) hipótesis acerca del tamaño del ara es correcta, tiene sentido la afirmación de Fernández Gil, contenida en el primer párrafo de la carta, en la que se dice que el receptáculo que el ara cubría parcialmente era de muy pequeñas dimensiones, tan pequeño como para que el investigador lo considere destinado a la deposición de cenizas y no de un cadáver, impresión que corrobora -según Fernández Gil- el hallazgo de carbones de algún tamaño ${ }^{40}$ en su

\footnotetext{
${ }^{39}$ Puede verse la transcripción íntegra de esta carta en el Apéndice I, $\mathrm{n}^{\circ} 3$.

${ }^{40}$ Suponemos que al referirse a esos carbones de algún tamaño, Fernández Gil quiere decir que no habrían podido depositarse accidentalmente en la cavidad, junto con la tierra lodosa que se había entrado por los intersticios.
} 
interior. Pero la finalidad columbaria del receptáculo choca-estimamos- con el antropomorfismo de su silueta, incluso con la presencia del poyete para reposar la cabeza. ¿Podría tratarse de una sepultura infantil, reaprovechada posteriormente como urna cineraria?

En otro párrafo de la carta, Fernández Gil plantea la posibilidad de que el ara de Trabanca hubiera formado parte de un monumento compuesto, situada en la parte anterior derecha del mismo; apoya esta suposición en la presencia de una moldura de sección semicircular que sirve como remate superior del plano frontal y el izquierdo del ara, moldura de la que no se aprecian restos en la parte posterior ni en la derecha. Especula también con la posibilidad de que el ara sirviera como soporte de alguna estatua en cuya basa hubiese un espigo que se introdugese por esa parte de la cornisa, aunque en ninguno de los dos dibujos que conocemos se aprecia la existencia de orificio -ni señal de él-que permita mantener tal conjetura.

El último párrafo referido al ara de Trabanca en la carta de marzo de 1917 ubica el lugar del hallazgo: una heredad a la derecha del camino que desde Trabanca da Torre conduce a Xiabre-Jiabre [...], cerca del lugar del hallazgo está el Castro d'a Bouza y cerca de este el lugar de Jovelle a que se refiere mi estudio del Boletín de la Academia de la Historia, $p .44$.

Precisamente esa referencia al Boletín de la Academia de la Historia sirve a Fernández Gil para cerrar las líneas dedicadas al ara de Trabanca y, dando un notable giro temático, preguntar a Casto Sampedro acerca de su "asunto académico" (suponemos que se refiere a su ingreso en la Academia de la Historia), al que se refiere en términos tan coloquiales como para escribir: ¿Podrá ser que en tanto tiempo no habrá rebentado ninguno de los 80 que dice el Reglamento, o será que la proposición no ha prosperado?. Obviaremos cualquier apostilla al desenfadado comentario acerca de los académicos remisos a reventar.

\section{CONCLUSIONES}

- La conocida como ara de Trabanca fue hallada entre 1885 y 1890 por el padre de Juan Fernández Gil y Casal en el lugar de Trabanca Badiña (parroquia de Arealonga, ayuntamiento de Vilagarcía de Arousa).

- Se trata de un paralelepípedo de piedra, tal vez de $42 \mathrm{~cm}$ de altura (según una referencia transversal, poco precisa), cuya única ornamentación consiste en una moldura semicircular convexa situada en el vértice superior de dos de sus caras.

- Presenta una inscripción votiva en la que se identifica claramente el dedicante (QvinTinvs Q. F.) y la fórmula votiva (v. s. L. M.); no hay, en cambio, unanimidad acerca de la identidad del dedicatario. 
- Cuando se encontró servía como cubierta parcial de un receptáculo antropomorfo de pequeñas dimensiones - que Fernández Gil califica de urna cineraria-, construido con tégulas y lastras de piedra, situada a la derecha del camino de Trabanca da Torre al monte Xiabre. En su entorno se hallaron restos de tégulas.

- La primera referencia impresa, tangencial, al ara de Trabanca es de 1904, y figura en Galicia antigua de Celso García de la Riega.

- Antes de mayo de 1909 ya se había perdido.

- En los primeros días de mayo de 1909 Fernández Gil realizó un dibujo a la aguada del ara -a partir de un boceto tomado del natural-, destinado a la Exposición Regional de Galicia. Con tal motivo volvió a intentar interpretar su contenido: el día 8 de mayo escribió a López Ferreiro, copiando la inscripción, para consultarle su hipotética interpretación; asimismo recurrió al padre Fidel Fita, como revela una carta dirigida a Casto Sampedro el 19 de mayo de 1909.

- En enero de 1915 Fernández Gil envió el manuscrito de sus "Apuntes arqueológicos" a la Real Academia de la Historia, en los que mencionaba el ara de Trabanca copiando la primera línea de texto del epígrafe y el signo que encabezaba la segunda. El artículo se publicó en el Boletín de la Real Academia de la Historia en 1916.

- En marzo de 1917 Fernández Gil escribió a Casto Sampedro para proporcionarle algunos datos acerca del ara de Trabanca que el director de la Sociedad Arqueológica de Pontevedra debió solicitarle previamente.

- En 1931 Casto Sampedro recoge algunas noticias acerca del hallazgo del ara y ofrece una lectura parcial del texto, aunque sin indicar la distribución en líneas. Respecto a su paradero - a pesar de que, como hemos visto, ya se consideraba perdida en 1909- afirma: No se pudo recoger aún a pesar de las muchas diligencias al efecto.

- A partir de 1931 se publican diversas referencias al ara de Trabanca (Álvarez Limeses, Filgueira Valverde \& García Alén, Bouza Brey, etc.) que reproducen noticias anteriores y no aportan datos sustanciales para su conocimiento; quizá lo más significativo es la duda que, acerca de la existencia del ara de Trabanca, plantean Filgueira Valverde y García Alén en 1953.

- En 1994 Gemma Baños incluye el ara de Trabanca en el Corpus de inscricións romanas de Galicia correspondiente a la provincia de Pontevedra, en el que ofrece una lectura parcial de la inscripción así como su organización en líneas tomada, posiblemente, de esa copia mecanografiada de orixe descoñecida cuya localización limita a No Museo de Pontevedra. 
- En 1996 José María Blázquez propuso la hipótesis de que el sujeto del voto que testimoniaba el ara de Trabanca era un dios indígena.

\section{APÉNDICE DOCUMENTAL ${ }^{41}$}

\section{1}

1909, mayo, 8.- Vilagarcía de Arousa.

Juan Fernández Gil y Casal escribe a Antonio López Ferreiro.

SANTIAGO DE COMPOSTELA, Museo do Pobo Galego, Fondo Blanco-Cicerón, pendiente de catalogación, orig.

Observaciones: Carta editada por Carlos Santos Fernández en Antonio López Ferreiro..., Epi. 164, págs. $882-883$.

\section{Sr. D. Antonio López Ferreiro. Santiago.}

Muy querido amigo y maestro. Al terminar una aguada-dibujo de la lápida Ari de que di a V. cuenta hace tiempo y que hoy reproduzco para la exposición ocurrióseme intentar una vez más su interpretación, y habiendo llegado a esta se la consulto. Ara a Júpiter (según el P. Fita) o a Ares, según Casto Sampedro y el muy intransigente Lariega [i.e: la Riega] siquiera el Ari no corresponda a ninguno de los casos de la declinación griega a que en tal caso debe sujetarse el Areo Arês Arêos Arei Arê o Arên y Ares Arei Arei Arem me parece en ambas lenguas considerándolo en la segunda como voz latina, si no estoy mal enterado, tendremos:

Ara a Júpiter o a Ares divino. Ladonio Nonio Quintino, hijo de Quinto, cumplió de buen grado y merecimiento su voto.

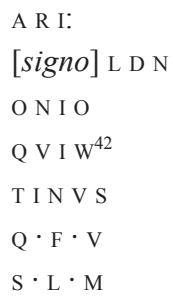

Le remito también esa lista por si por casualidad alguno pudiera interesarle para sus trabajos, aun que supongo que siendo como serán copias, tendrá V. ya conocimiento de los originales.

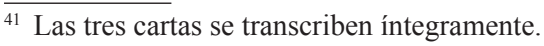

${ }^{42}$ Aunque, según la lectura, se trata de la $\mathrm{N}$ postnuclear de la primera sílaba, Fernández Gil traza en esta posición una $\mathrm{W}$.
} 
¿Sirve para la Exposición algo de lo que comprende la relación que le remití anteriormente? ¿Qué se remite de todo ello?

Sin más, esperando su parecer, se repite como siempre aff. amigo y s. s. q. s. m. b.

[Firmado:] J. Fernández Gil y Casal.

Villagarcía 8 mayo 1909.

\section{2}

1909, mayo, 19.- Vilagarcía de Arousa.

Juan Fernández Gil y Casal escribe a Casto Sampedro.

PONTEVEDRA, Museo de Pontevedra, Fondo Casto Sampedro, carp. 67-62, sin núm., orig.

Sr. D. Casto Sampedro. Pontevedra.

Pues sí mi querido amigo: no estoy conforme con su carta, pues creo recordar que cuando V. me dijo que escriviría al P. Fita sobre la lápida le advertí que al hablarle de su hallazgo le dijera que había sido en la circunscripción de Trabanca Badiña, cerca del lugar de la Torre, y ahora añadiré (estilo del P. Sarmiento) que antiguamente, cuando aquella parte del campo estuvo menos poblada, pudo cuadrar perfectamente y por estensión el nombre de lugar de Trabanca a una superficie de terreno de más de un cuarto de legua por no existir en toda esa estensión más que una aldea (lo que dudo), pero al presente en que hay en él varios grupos de población, había que mudar el nombre de lugar por el de su circunscripción y dar el nombre de lugares a los diferentes grupos de casas que con sus nombres distintos existen hoy en la tal Trabanca, quedándole este nombre íntegro al lugar que así se llama, único que pudo encontrar el P. Fita en el Madoz. Bueno ahora me se [sic] ocurre que pudo y debió llamarse Trabanca todo ese terreno y el tal lugar recibir el nombre de él, ya que en las mismas condiciones hay dos porciones de territorio que se apellidan Trabanca Badiña y Trabanca Sardiñeira ¿Y por qué se llaman trabancas, qué significa este apelativo? ¿Y por qué se llamó calle de la Trabanca la de la Herrería de esa? ¿Se derivará de trabaria, ya que ambas localidades están próximas a la costa?

Y volvamos a la lápida.

Forma el sepulcro [dibujo de $90 \times 115 \mathrm{~mm}$ ].

Formado con tejones gruesos y lastras, cubriendo el ara una parte de él y estando el resto cubierto con lastras.

Deposito en él: tierra negra.

Dirección: la que se indica E a O.

Fecha: del 1885 al 1890. 
En el mismo terreno se encontraron restos de tégulas en una extensión regular.

Supongo no se olvidará de mi encargo, ni de decirme la opinión del docto jesuita sobre la interpretación referente a la piedra.

¿Quien va a esa a fotografiar lo fotografiable para la Exposición? A esta mi "pequeña provincia" me dijo Ferreiro mandará a un tal Limia, sacerdote, y en comisión de 2 la recorreremos.

Adiós.

Suyo affmo.

[Firmado:] J. Fernández Gil y Casal

Villagarcía, 19 mayo 1909.

1917, marzo, 8.- Vilagarcía de Arousa.

Juan Fernández Gil y Casal escribe a Casto Sampedro.

PONTEVEDRA, Museo de Pontevedra, Fondo Casto Sampedro, carp. 67-62, núm. 1, orig.

Amigo D. Casto: la lápida en cuestión cubría, en parte, una sepultura de muy pequeñas dimensiones que por tener tierra lodosa que se había entrado por los intersticios mezclada con carbones de algún tamaño, entiendo que debió servir de urna cineraria por lo cual el tamaño de la lápida debe ser el más aproximado.

Como la copia esa fue dibujada por medio de cuadrículas hay por lo tanto proporción en todas sus partes; considerando que el dibujo primero tomado del natural fue copiado con la conciencia que acostumbro a poner en todas mis cosas. Ahora bien; como no puedo precisar si las letras tal cual en esa copia están reproducidas, son unos milímetros más o menos grandes con relación a las originales aunque creo recordar que si no son iguales se le deben acercar mucho, considerando que el tamaño de ellas es el más corriente creo que reproduciéndolo tal y como está ahí se aproxima a la verdad.

La piedra debió de formar parte de otro monumento, al rededor [sic] del cual corría una pequeña cornisa, debiendo ser esa la piedra de la derecha con relación al que mira y esquina del tal, y aun se me ocurre si tendría encima alguna estatua en cuya basa hubiese un espigo que se introdugese por esa parte de la cornisa y ocurriese lo mismo en la otra piedra pareja.

Para completar datos conviene saber que fue encontrada en una heredad a la derecha del camino que desde Trabanca da Torre conduce a Xiabre-Jiabre y que cerca del lugar del hallazgo está el Castro d'a Bouza y cerca de este el lugar de Jovelle a que se refiere mi estudio del Boletín de la Academia de la Historia, p. 44.

Y a propósito ¿qué sabe V. de mi asunto académico? Podría V. poner dos letras o tres a ese su amigo porque para después de la guerra me convenía tener eso resuelto ¿Podrá ser que 
en tanto tiempo no habrá rebentado ninguno de los 80 que dice el Reglamento, o será que la proposición no ha prosperado? Después de lo que del caco se ha dicho no sería mal ridículo.

Días pasados escribí al librero de la Academia para que me remitiese un reglamento y me digese su coste para remitírselo y me lo remitió en efecto, pero se calló en lo demás como un muerto. Todo esto es estraño ¿tomo? o no tomo? de la casa.

Mande a su afmo. amigo q. s. m. b.

[Firmado:] J. Fernández Gil y Casal.

Villagarcía, 8 marzo 1917.

P. E. Felicidades por la reelección.

\section{BIBLIOGRAFÍA}

"Academia de la Historia”, La Correspondencia de España, 26 de febrero de 1915, pág. 5.

Aguilera y Gamboa, Enrique de (marqués de Cerralbo), “Apuntes arqueológicos por el Sr. D. Juan Fernández Gil y Casal, en comunicación manuscrita que ha dirigido a la Real Academia de la Historia", Boletín de la Real Academia de la Historia, 68 (enero-junio de 1916), págs. 46-55.

Álvarez Limeses, Gerardo, Geografia general del Reino de Galicia. Dirigida por F. Carreras Candi. Provincia de Pontevedra, Barcelona, Alberto Martín, 1936.

Baños Rodríguez, Gemma, Corpus de inscricións romanas de Galicia. II. Provincia de Pontevedra, Santiago, Consello da Cultura Galega, 1994.

Barreiro Fernández, Xosé Ramón, Murguía, Vigo, Galaxia, 2012.

Blázquez Martínez, José María, "Religiones indígenas en la Hispania romana (addenda et corrigenda)", Gerión, 14 (1996), págs. 333-362.

Bouza Brey, Fermín, "Nuevos epígrafes de la Galicia romana", Boletín de la Comisión Provincial de Monumentos Históricos y Artísticos de Orense, 249 (noviembre-diciembre de 1939), págs. 193-203.

Bouza Brey, Fermín, "O castro de Alobre e os contactos antre a Bretaña e a Galiza na época romana" en Homaxe dos amigos e discípulos do petrucio da Prehistoria galega, Florentino L. A. Cuevillas, no LXX aniversario do seu nacimento, Vigo, Galaxia, 1957, págs. 73-110.

Fernández Gil y Casal, F. [i. e: J.], “Apuntes arqueológicos”, Boletín de la Real Academia de la Historia, 68 (enero-junio de 1916), págs. 29-46.

Filgueira Valverde, José y Alfredo García Alén, Materiales para la carta arqueológica de la provincia de Pontevedra, Pontevedra, Museo de Pontevedra, 1953.

Filgueira Valverde, José y Álvaro D’Ors, Inscripciones romanas de Galicia. III. Museo de Pontevedra, Santiago, CSIC - Instituto Padre Sarmiento, 1955.

García de la Riega, Celso, Galicia antigua. Discursos acerca de su geografia y de su historia, Pontevedra, Diputación Provincial de Pontevedra, 1904.

Sampedro, Casto, "Aras romanas en el Museo de la Sociedad Arqueológica de Pontevedra" en José Cao Moure (ed.), Libro de oro de la provincia de Pontevedra, [Pontevedra], José Cao Moure (РРКо), 1931, págs. 32-34. 
Santos Fernández, Carlos, Antonio López Ferreiro (1837-1910). Canónigo compostelano, historiador y novelista, Santiago, Cabildo de la Catedral de Santiago - Consorcio de Santiago - Alvarellos Editora, 2012.

Santos Fernández, Carlos, "Correspondencia sobre la estela romana de Araño (Rianxo) conservada en el Museo de Pontevedra”, Cuadernos de Estudios Gallegos, 61 (2014), págs. 319-374

X, "Indicaciones epigráficas desde la Guardia a Santiago" en Mondariz, Vigo, Santiago. Guía del turista, Madrid, Sucesores de Rivadeneyra, 1912, págs. 58-69.

Zarzalejos Prieto, M. Mar, “Aproximación al panorama historiográfico de la cultura castreña en la provincia de Orense (I)", Cuadernos de Prehistoria y Arqueología de la Universidad Autónoma de Madrid, 16 (1991), págs. 297-312. 